\title{
Péptidos que atraviesan la membrana celular como poten- ciales transportadores de fármacos
}

\author{
Cell Penetrating Peptides as potential drug carriers \\ Ximena Carolina Pulido ${ }^{1,2,3}$, Miriam Royo ${ }^{2,3}$, Fernando Albericio ${ }^{2,3,4,5}$ y Hortensia Rodríguez $z^{3,4,6}$
}

DOI. 10.21931/RB/2016.01.04.9

\section{RESUMEN}

El descubrimiento y desarrollo de secuencias peptídicas (naturales o sintéticas), así como de peptidomiméticos que puedan penetrar en las células (CPPs, por sus siglas del inglés: Cell penetrating peptides), constituye un avance prometedor en la identificación de entidades capaces de promover la entrega no invasiva e íntegra de moléculas pequeñas, ADN plasmídico, ARN de interferencia, proteínas, virus y nanopartículas, entre otras, al interior de la célula. Por lo general, estas secuencias peptídicas están compuestas de 5-30 aminoácidos y se pueden clasificar en catiónicos, anfipáticos e hidrofóbicos, teniendo en cuenta sus características estructurales. La presente revisión explora la clasificación y el estado del arte en general de esta temática, con especial énfasis en el tipo de unión entre el péptido con capacidad de atravesar la membrana celular (CPP) y la entidad a transportar.

Palabras clave: Péptidos, Barrera hematoencefalica, transportadores moleculares, CPPs

\section{ABSTRACT}

The discovery and development of natural, synthetic or peptidomimetic cell-penetrating peptides (CPPs) is a promising breakthrough to achieve non-invasive delivery of non-permeable biomolecules in the intracellular compartment. The CPPs are able to carry small molecules, plasmid DNA, interfering RNA, proteins, viruses, nanoparticles among others, across the cellular membrane, resulting in internalization of the intact cargos. In general, are sequence with 5-30 aminoacids, which are classified in cationics, amphipathics or hydrophobics, depending on its structural characteristics. The present review explores the classification, as well as the "state of the art" of this topic, focuses on the link between CPP and cargo.

Keywords: Peptides, Molecular transportes, cell penetrating peptides, blood-brain barrie

\section{Introducción}

Las barreras biológicas son las interfaces generadas durante la evolución, que hicieron posible que los organismos abandonaran el agua y se establecieran en la tierra. Durante el proceso evolutivo, la necesidad de especificación promovió su diferenciación, con el fin de regular procesos como la homeostasis del agua, la entrada de nutrientes, el intercambio de gases o la excreción de compuestos tóxicos. ${ }^{1}$ Las barreras biológicas más estudiadas incluyen la piel, las membranas mucosas, la barrera hematoencefálica (BHE) y las barreras celulares. Estas últimas (por ejemplo, el núcleo o la mitocondria) constituyen las barreras de mayor importancia biológica si nos interesa potenciar el transporte de fármacos a través de ellas para mejorar la efectividad de los agentes terapéuticos. ${ }^{1,2}$
Las membranas celulares son las responsables de la comunicación y el transporte de iones y nutrientes. El transporte de moléculas a través de estas barreras comprende desde la entrada de nutrientes del ambiente, hasta la salida de moléculas tóxicas. Son estos procesos naturales de transporte los que se utilizan para incorporar entidades terapéuticas al organismo, cuya eficacia dependerá, en gran medida, de su capacidad de atravesar dichas barreras. ${ }^{1}$ Factores como: la expulsión de las moléculas por los transportadores de salida, ${ }^{1}$ su degradación in vivo mediada por enzimas proteolíti$\operatorname{cas}^{2}$ y la baja permeabilidad de la barreras biológicas frente a las biomoléculas, limitan la distribución de compuestos terapéuticos y constituyen uno de los retos actuales de la biomedicina. ${ }^{1,2}$

${ }^{1}$ Departamento de Química, Facultad de Ciencias, Universidad del Tolima, 546 Ibagué, Colombia

2Unidad de Química Combinatoria, Parque Científico de Barcelona, Baldiri Reixac 10, 08028 Barcelona, España

${ }^{3}$ Centro de Investigación Biomédica en red. Bioingeniería, Biomateriales y Nanomedicina (CIBER-BBN), España

${ }^{4}$ Departamento de Química Orgánica, Universidad de Barcelona, 080028 Barcelona, España

${ }^{5}$ Escuela de Química, Universidad Kwa-Zulu-Natal, 4001 Durban, Sudafrica.

${ }^{6}$ Escuela de Química, Yachay Tech, Ciudad del conocimiento Yachay, Urcuqui, Ecuador

Correspondencia: Ximena Carolina Pulido. Departamento de Química, Facultad de Ciencias, Universidad del Tolima e-mail: xpulido@ut.edu.co 
Los factores anteriormente mencionados, conllevan a que los sistemas de administración de fármacos se diseñen como plataformas terapéuticas que interaccionen con estas barreras y faciliten la administración de un determinado principio activo a un tejido o tipo de célula específica. Durante las dos últimas décadas, la conjugación de compuestos con alto interés terapéutico a moléculas capaces de atravesar las membranas celulares conocidas como transportadores moleculares, se ha utilizado ampliamente como estrategia de punta en el área de la administración de fármacos. El objetivo de estos procedimientos es la búsqueda continua del incremento de la permeabilidad celular en determinados tejidos o células para favorecer la administración de fármacos. Esta revisión, pretende describir el estado del arte de la temática que enmarca a una gran variedad de péptidos (naturales o sintéticos) capaces de travesar la membrana celular (CPPs, por sus siglas del inglés: Cell penetrating peptides) que se han utilizado en los últimos años como transportadores moleculares eficientes, remarcando el tipo de unión generado entre el principio activo y la secuencia peptídica.

\section{Antecedentes y generalidades de los CPPs}

Sin lugar a dudas, el descubrimiento de determinados péptidos naturales con capacidad de atravesar la membrana celular marca el inicio de esta temática. Estas biomoléculas emergieron como una clase especial de transportadores, que constituyen una de las herramientas más utilizadas en el transporte intracelular no invasivo de fármacos, al unirse a principios activos mediante la formación de enlaces químicos o por la formación de complejos estables no covalentes. ${ }^{3}$ La capacidad de transporte de los CPPs, permitió la internalización celular de moléculas de distinto grado de complejidad con propiedades terapéuticas, como moléculas pequeñas, ${ }^{4,5}$ ácidos nucleicos, ${ }^{6,7}$ proteínas, ${ }^{8}$ liposomas, ${ }^{4,9}$ quantum dots $^{10} \mathrm{y}$ agentes de contraste de resonancia magnética, ${ }^{11}$ entre otros.

Los CPPs comprenden una gran diversidad de secuencias y estructuras, pero presentan características similares que son las responsables de su capacidad de atravesar la membrana citoplasmática y alcanzar el interior de la célula, otorgándole a estas estructuras varias ventajas con respecto a otros transportadores. ${ }^{4,9,12,13,14}$ (Figura 1). especificidad, lo que disminuye su interacción con otras moléculas y la probabilidad de producir efectos secundarios. Además, presentan baja acumulación en los tejidos y no generan metabolitos secundarios, lo que les confiere baja toxicidad. ${ }^{23}$ Sin embargo, los CPPs tienen un uso limitado debido a su baja biodisponibilidad, la cual se asocia a su baja resistencia frente a proteasas, que conjuntamente con el hecho de quedar embebido en los endosomas, conduce a una rápida degradación de los mismos, siendo incapaces de llegar al citosol o al sitio de interés. ${ }^{24}$ En general, estos péptidos presentan algunas desventajas con respecto a otras moléculas terapéuticas tradicionales, como un mayor costo de síntesis y su baja vida media; esta última debido a que al carecer de estructura terciaria, son particularmente sensibles a la degradación enzimática. ${ }^{25}$

Con el fin de superar estos inconvenientes, se han desarrollado oligómeros conocidos como plegómeros (foldamers) que mimetizan péptidos naturales. El termino plegómero fue acuñado por Gellman para definir a cualquier oligómero, que en solución es capaz de plegarse en un estado conformacionalmente ordenado. ${ }^{26}$ Estas estructuras se estabilizan mediante interacciones no covalentes entre las unidades de monómeros no adyacentes que conforman el plegómero, favoreciendo una estructura secundaria definida. La investigación en la química de estos compuestos ha permitido explorar el plegamiento de esqueletos no naturales para entender la relación secuencia-plegamiento en los oligómeros naturales y desarrollar nuevos oligómeros que mimetizen polímeros naturales con diferentes aplicaciones terapéuticas. ${ }^{27}$ Dentro de los plegómeros más estudiados, los péptidos ocupan un lugar importante debido a que cubren un amplio rango de aplicaciones biomédicas (Figura 2). En esta categoría de compuestos se incluyen los beta-péptidos, ${ }^{28}$ los $\gamma$-péptidos ${ }^{29} \mathrm{y}$ los péptidos cuya secuencia está compuesta por D-aminoácidos.

La capacidad de permeabilidad celular de determinadas secuencias como el Tat ha impulsado en los últimos años, las investigaciones en esta área de los péptidos Penetradores en la Célula (CPP, Cell Penetrating Peptides), en busca de secuencias aminoacídicas que faciliten la entrada de agentes terapéuticos a la célula. ${ }^{2}$ (Figura 3) Nuestro grupo ha sido pionero en la investigación de plegómeros como CPP, concretamente $\gamma$-peptidos derivados de las 4-aminoprolina.

\section{Péptidos que atraviesan la membrana celular (CPPs)}

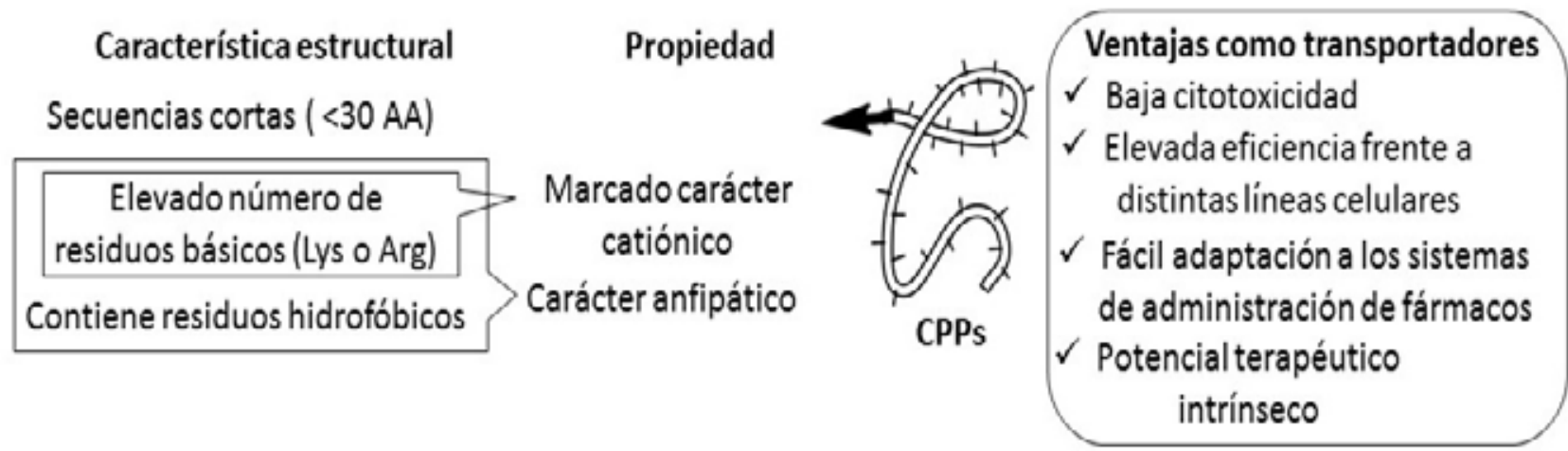

Fig. 1. Relación estructura/propiedad y ventajas como transportadores de los péptidos que atraviesan las membranas celulares (CPPs).

En este contexto, la secuencia peptídica conocida como Tat, correspondiente al fragmento (48-60) del dominio básico de la proteína Tat del virus de inmunodeficiencia humana, ${ }^{2,15}$ ha sido el CPPs más estudiado y prometedor como transportador de fármacos. ${ }^{15}$ Además, otras secuencias como el pAntp (también conocido como penetratina), ${ }^{16}$ las poliargininas, ${ }^{17,18}$ el MPG,${ }^{19}$ el Pep- $1,{ }^{20}$ el $\mathrm{pVEC}^{21}$ y péptidos derivados de la calcitonina humana ${ }^{22}$ se han desarrollado como eficientes CPPs y potenciales transportadores de fármacos.

Desde el punto de vista terapéutico, los péptidos son particularmente atractivos ya que presentan actividad biológica y alta

\section{Clasificación de los CPPs.}

Los CPPs pueden clasificarse en subgrupos definidos por su origen o las características de su secuencia. ${ }^{15}$ Hasta la fecha, se conocen más de $800 \mathrm{CPPs}$ de orígenes y características diversas. La mayoría de los CPPs presentan una carga neta positiva (83\%), también se encuentran CPPs aniónicos que no forman ninguna categoría propia y son asignados a las otras diferentes clases (anfipática e hidrofóbica) analizándolos caso por caso. ${ }^{24}$ Los péptidos anfipáticos, formados tanto por catiónicos como por aniónicos constituyen el $44 \%$ de todos los CPPs, mientras los hidrofóbicos solo el $15 \%$. El estado del arte de la temática permite demostrar la 
elevada variedad de estos péptidos teniendo en cuenta las secuencias, el origen, la función y las aplicaciones biomédicas de cada uno de ellos. ${ }^{2}$ Teniendo en cuenta las propiedades físico-químicas de los CPPs, es posible clasificarlos en tres subgrupos principales: catiónicos, anfipáticos o hidrofóbicos (Tabla 1). 2,9,15 se encuentran el Tat, el R9, ${ }^{31}$ el hLF y el (RXR) ${ }^{4}$, entre otros (Tabla 1). Algunos trabajos agrupan dentro de esta categoría aquellos péptidos con carga neta positiva necesaria para la internalización celular, pero que no forman una hélice anfipática. ${ }^{24}$



Fig. 2. Aplicaciones biomédicas de los plegómeros peptídicos.



Fig. 3. Aplicaciones de los CPPs como transportadores moleculares.

*IMR: por sus siglas del Inglés, Imaging Magnetic Resonance (Imágenes obtenidas mediante resonancia magnética).

\section{CPPs catiónicos.}

Los péptidos catiónicos son aquellos que presentan una carga neta positiva elevada. Diversos estudios realizados sugieren que al menos se necesitan ocho cargas netas positivas para una eficiente absorción de estos compuestos. ${ }^{24}$ Estas moléculas fueron originalmente consideradas como vehículos de transporte de tipo "caballos de Troya", internalizándose en las células sin generar respuesta. ${ }^{30} \mathrm{Sin}$ embargo, los péptidos catiónicos pueden inducir un amplio rango de efectos secundarios relacionados con la integridad de la membrana celular y la viabilidad celular, los cuales pueden resultar más sutiles de determinar que la muerte celular. Dentro de los CPPs de carácter catiónico más estudiados

\section{CPPs hidrofóbicos.}

Los CPPs hidrofóbicos son aquellos que contienen sólo residuos apolares. Dentro de esta familia se encuentran los péptidos grapa (stapled peptides), ${ }^{32}$ los prenilados ${ }^{33}$ y el pepducin. ${ }^{34}$ Hasta el momento, solo unos pocos CPPs de carácter hidrofóbico han sido descubiertos, como son los derivados de secuencias de señalización de la proteína beta 3 integrina (VTVLALGALAGVGVG) y del factor de crecimiento de fibroblastos Kaposi. ${ }^{35}$ Los CPPs anfipáticos como el MAP ${ }^{36}$ y otros CPPs quiméricos de cadenas largas, están compuestos por aminoácidos hidrofóbicos y adicionalmente, presentan residuos catiónicos que incrementan la permeabilidad de la membrana (Tabla 1 ). ${ }^{37}$ 


\begin{tabular}{|c|c|c|}
\hline CPPs & Secuencia & Origen \\
\hline \multicolumn{3}{|l|}{ Catiónicos } \\
\hline Tat $(48-60)$ & GRKKRRQRRRPPQ & Dominio VIH-Tat \\
\hline Penetratina & RQIKIWFQNRRMKWKK & Homodominio de Antennapedia \\
\hline R9 & RRRRRRRRR & Sintético \\
\hline Poliargininas & $(\mathrm{R})_{\mathrm{n}} 6<\mathrm{n}<12$ & Sintéticos \\
\hline R6W3 & RRWWRRWRR & Sintético \\
\hline (RXR)4 & $\left(\mathrm{R}-\mathrm{Ahx} \mathrm{x}^{8}-\mathrm{R}\right) 4$ & Sintético \\
\hline \multicolumn{3}{|l|}{ Anfipáticos } \\
\hline MPG & $\begin{array}{l}\text { GALFLGFLGAAGSTMGAWSQPKK } \\
\text { KRKV }\end{array}$ & gp41-VIH/antígeno T SV40 \\
\hline pVEC & LLIILRRRIRKQAHAHSK & Cadherina (615-632) \\
\hline CADY & GLWRALWRLLRSLWRLLWRA & Sintético \\
\hline vT5 & $\begin{array}{l}\text { DPKGDPKGVTVTVTVTVTGKGDP } \\
\text { KPD }\end{array}$ & Proteinas virales \\
\hline $\operatorname{ARF}(1-22)$ & MVRRFLVTLRIRRACGPPRVRV & Proteina p14ARF \\
\hline MAP & KLALKLALKAALKLA & Quimérico \\
\hline Pep-1 & KETWWETWWTEWSQPKKKRKV & Racimo enriquecido con triptófanos \\
\hline \multicolumn{3}{|c|}{ Péptidos ricos en prolinas } \\
\hline Bac-7 & RRIRPRPPRLPRPRPRPLPFPRPG & $\begin{array}{l}\text { Péptidos antimicrobianos de la familia de } \\
\text { la Bactenecin }\end{array}$ \\
\hline$(\mathrm{PPR}) \mathrm{n}$ & (PPR)3, (PPR)4, (PPR)5, (PPR)6 & Sintéticos \\
\hline$(\mathrm{PRR}) \mathrm{n}$ & (PRR)3, (PRR)4, (PRR)5, (PRR)6 & Sintéticos \\
\hline aPP4R1 & $\begin{array}{l}\text { GPSQPTYPGDDAPVRDLIRFYRDL } \\
\text { QRYLNVVTRHRY }\end{array}$ & \multirow[t]{3}{*}{ Sintéticos } \\
\hline aPP5R1 & $\begin{array}{l}\text { GPSQPTYPGDDAPVRDLIRFYRDL } \\
\text { RRYLNVVTRH }\end{array}$ & \\
\hline aPP6R1 & $\begin{array}{l}\text { GPSQPTYPGDDAPVRDLRRFYRD } \\
\text { LRRYLNVVTRHRY }\end{array}$ & \\
\hline $\begin{array}{l}\text { P8LKK } \\
\text { P11LKK } \\
\text { P8LRR } \\
\text { P11LRR }\end{array}$ & $\begin{array}{l}\mathrm{FL}-\mathrm{G}\left(\mathrm{P}_{\mathrm{LXX}}\right)_{\mathrm{n}} \mathrm{PL}_{\mathrm{L}}-\mathrm{CONH}_{2} \\
\mathrm{X}=\mathrm{P}_{\mathrm{K}} \circ \mathrm{P}_{\mathrm{R}}, \mathrm{n}=2 \circ 3\end{array}$ & Sintéticos \\
\hline SAP & VRLPPPVRLPPPVRLPPP & Sintético \\
\hline SAP(E) & VELPPPVELPPPVELPPP & Sintético \\
\hline \multicolumn{3}{|l|}{ Hidrofóbicos } \\
\hline PFV & PFVYLI & $\mathrm{C} 105 \mathrm{Y}$ \\
\hline SG3 & RLSGMNEVLSFRWL & Quimioteca peptídica aleatoria \\
\hline Pep-7 & SDLWEMMMVSLACQY & CHL8 \\
\hline FGF & PIEVCMYREP & Proteínas virales y celulares \\
\hline
\end{tabular}

Table 1. CPPs representativos de cada subgrupo. $2,{ }^{14}$

\section{CPPs anfipáticos.}

Se definen como péptidos anfipáticos aquellos que contienen en su estructura regiones polares y apolares. ${ }^{24}$ Se incluyen en este subgrupo el MPG, ${ }^{19}$ la penetratina o pAntp $^{16}$ y el CADY (Tabla 1), en los cuales el carácter anfifílico se encuentra estrechamente relacionado con su estructura primaria.

Algunos CPPs como el MPG, son péptidos quiméricos obtenidos mediante la unión covalente de un dominio hidrofóbico como diana de las membranas celulares a una secuencia de localización celular (SLC). Otros CPPs anfipáticos son derivados de proteínas naturales, como el pVEC, el ARF (1-22) y el BPrPr (1-28).

Los CPPs anfipáticos con estructura secundaria de tipo alfa-hélice contienen una parte altamente hidrofóbica, mientras que la parte polar puede ser catiónica, aniónica o sin carga. Aquellos con estructura secundaria de tipo lámina beta, se basan en alternar secuencias hidrofóbicas e hidrofílicas que se encuentran expuestas al disolvente, como el vT5. ${ }^{24}$

\section{Péptidos ricos en prolina como atractiva familia de CPPs anfipáticos.}

Los péptidos ricos en prolinas constituyen otra clase interesante de CPPs anfipáticos que han sido estudiados en diversas familias, diferentes en secuencia y estructura, pero con presencia del fragmento prolina (esqueleto pirrolidínico) como característica común. La prolina se caracteriza por poseer el anillo pirrolidí- nico, el cual induce rigidez conformacional cuando está presente en un esqueleto peptídico. A pesar de su carácter hidrofóbico, los péptidos ricos en prolina tienen la gran ventaja de ser solubles en agua y en diferentes disolventes orgánicos. ${ }^{38}$

Debido a las propiedades de la prolina, los péptidos ricos en este aminoácido pueden adoptar dos estructuras secundarias: la poliprolina I (PPI) y la poliprolina II (PPII). La PPI es la conformación principal en presencia de alcoholes alifáticos, mientras que la PPII es la conformación principal en medio acuoso o en presencia de ácidos alifáticos. La PPI forma una hélice compacta dextrógira, compuesta por 3,3 residuos por giro, en la cual los enlaces peptídicos adoptan la conformación cis. Por otra parte, la PPII forma una hélice extendida levógira, que está compuesta de tres residuos por giro, con todos los enlaces peptídicos en conformación trans. Debido al proceso de equilibrio existente entre ambos isómeros conformacionales (cis/trans) asociado a los enlaces peptídicos, las secuencias peptídicas ricas en prolina pueden alternar en solución entre las dos estructuras secundarias anteriormente descritas, mediante un simple cambio del disolvente. ${ }^{38}$

Varios trabajos han demostrado que algunos péptidos ricos en prolina pueden ser considerados CPPs ya que internalizan en células eucarióticas. ${ }^{39}$ Además, esta clase de CPPs presentaron propiedades de autoensamblaje interesantes que fueron estudiadas mediante dicroísmo circular (DC) y microscopía electrónica 
de transmisión (TEM, transmission electron microscopy). Algunos de los péptidos pertenecientes a este grupo, son derivados del dominio N-terminal de la $\gamma$-zeína (proteína de almacenamiento del maíz). Otros, como el Bactenecin-7 (Bac-7) están sintéticamente basados en hélices de poliprolina basadas en la repetición del motivo PRP. ${ }^{39}$

Dentro de los CPPs ricos en prolina más estudiados hasta la fecha, es posible distinguir dos categorías dependiendo de si los aminoácidos presentes en la secuencia peptídica son o no naturales:

\section{i) CPPs lineales ricos en prolina compuestos por aminoácidos naturales.}

Este grupo está integrado por aquellas secuencias lineales formadas por aminoácidos naturales, pero también por otras más sofisticadas con estructuras dendriméricas. ${ }^{38}$ Tam y cols. ${ }^{40}$ utilizaron una proteína de 59 residuos conocida como Bac-7 (Tabla 1), que pertenece a la familia de la Bactenecin, como patrón para el diseño de CPPs. Esta proteína mostró actividad antimicrobiana mediante la inhibición intracelular de la maquinaria de la síntesis proteica. Desde el punto de vista estructural presenta una elevada densidad de carga neta positiva y posee 3 copias de una cadena de 14 residuos. Los estudios realizados en base a la estructura de Bac-7 permitieron acceder a nuevos CPPs en los cuales todas las secuencias contienen el motivo Pro-Xaa y permiten la absorción de la NeutrAvidin por parte de las células. Estos CPPs mostraron estructuras secundarias híbridas entre una alfa-hélice y una PPII, debido al alto contenido de prolinas presente en los mismos. ${ }^{40}$

Dentro de esta categoría, también se encuentran los CPPs ricos en prolina derivados del dominio $\mathrm{N}$-terminal de la $\gamma$-zeína, (proteína de almacenamiento del maíz). Desde el punto de vista estructural, esta proteína contiene tres dominios: un dominio $\mathrm{N}$-terminal rico en prolina, un dominio repetitivo central (PX)n y un dominio C-terminal rico en cisteínas. El dominio g-ZNPRD contiene la secuencia (VXLPPP)8, que es la responsable de dirigir la proteína hacia el retículo endoplasmático. ${ }^{37}$

\section{ii) CPPs lineales miméticos de prolina: g-péptidos.}

Dentro de los péptidos miméticos con capacidad de atravesar membranas celulares se encuentran los $\gamma$-péptidos sintetizados a partir de la cis- $\gamma$-amino-L-prolina, cuyo esqueleto se construye a través del grupo $\gamma$-amino (Figura 4). Estos péptidos pueden ser funcionalizados en los grupos alfa-amino de cada monómero mediante reacciones de acilación, alquilación o guanidilación para obtener entidades peptídicas con características hidrofóbicas, hidrofílicas o anfipáticas, ${ }^{3}$ como los hexapéptidos funcionalizados con guanidinios (Na-guanidil-g-hexapéptido) o con grupos alquílicos (Na-alquil-g-hexapéptido), que unidos a un fragmento di-oxa-octanoico, mostraron capacidad de atravesar la membrana celular en células HeLa y COS- $1 .{ }^{41}$
Fmoc y Boc en fase sólida (estrategia Fmoc/Boc), donde el Fmoc fue el grupo protector temporal para el grupo $\gamma$-amino de cada monómero y el Boc el grupo protector semipermanente para el grupo alfa-amino. El esqueleto de estos péptidos contiene enlaces peptídicos entre la función carboxílica y la función $\gamma$-amino de los residuos sucesivos. Estos $\gamma$-péptidos presentaron baja citotoxicidad incluso a altas concentraciones, estabilidad frente a la proteólisis enzimática y en general buena solubilidad. ${ }^{42,43}$ Además, la capacidad de estos péptidos de actuar como transportadores se corroboró cuando uno de los $\gamma$-péptidos sintetizados se conjugó a nanopartículas de óxido de hierro y se demostró que eran capaces de favorecer la internalización en células HeLa. ${ }^{43}$ Todas las propiedades de los $\gamma$-péptidos mencionadas anteriormente hacen que estos compuestos puedan ser considerados candidatos para ser utilizados como transportadores de moléculas con valor terapéutico.

Secuencias Peptídicas capaces de atravesar la membrana celular: tipos de unión.

Los CPPs se han utilizado para vencer las limitaciones extracelulares e intracelulares y favorecer la entrada de otras entidades a las células. Los CPPs se unen a moléculas biológicamente activas (principio activo) y las transportan a través de las membranas celulares hasta alcanzar el citoplasma y/u otros orgánulos celulares (Figura 3). De esta manera, se mejora el tráfico intracelular y se facilitan las interacciones con las dianas moleculares. ${ }^{3,44}$ Para la formación de estos híbridos moleculares, se han descrito dos estrategias basadas en el tipo de unión entre el CPP y la molécula terapéutica. Estas uniones pueden ser de carácter covalente mediante la formación de una gran variedad de enlaces en los que podrían intervenir grupos funcionales como $-\mathrm{NH}_{2},-\mathrm{COOH}$, - $\mathrm{SH}$, formación de heterociclos, entre otros; así como de carácter no covalente, generando complejos moleculares entre ambas moléculas (CPP y la molécula terapéutica) $)^{3,45}$ (Figura 5). tica.

\section{Híbridos covalentes entre el CPP y la molécula terapéu-}

Se consideran híbridos covalentes CPP-molécula terapéutica aquellos en los que ambas entidades están unidas a través de un enlace químico covalente, incluyendo tanto aquellos compuestos en que la unión se realiza mediante métodos químicos o bioconjugación, (Figura 5) como híbridos de carácter proteíco que se obtienen mediante la clonación de la proteína terapéutica fusionada al CPP y posterior expresión de la misma. ${ }^{3}$

Aunque los métodos de conjugación química ofrecen varias



L-prolina

\section{cis- $\gamma$-amino-L-prolina}

Fig. 4. gamma-péptidos derivados de prolina.

Farrera-Sinfreu y col. ${ }^{41}$ reportaron la síntesis y el estudio del potencial de actividad biológica de $\gamma$-péptidos, algunos de los cuales tienen la habilidad de atravesar membranas celulares. La quimioteca incluía péptidos formados por $\gamma$-amida oligómeros de cis- $\gamma$-amino-L-prolina, con diferentes modificaciones en el grupo alfa-amino (acilo, alquilo y guanidinio) que mimetizaban las cadenas laterales de los aminoácidos naturales. ${ }^{42}$ Estos péptidos se sintetizaron utilizando la combinación de dos grupos ortogonales

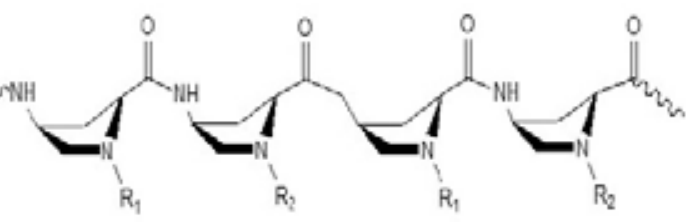

$\gamma$-péptido ventajas como la posibilidad de racionalización y el control del híbrido molecular formado, se debe tener en cuenta que el enlace covalente que se genera podría inducir cambios estructurales capaces de alterar la actividad biológica de la molécula a transportar. $^{29}$

Los métodos de conjugación más utilizados para la unión del CPP a la molécula a transportar utilizan el grupo tiol de una cisteína, introducida en uno de los extremos del CPP y/o en la 
molécula a transportar para formar puentes disulfuro o un anillo tiazolidínico. En el caso de la formación de enlaces disulfuros, el ambiente reductivo de la célula facilita la escisión de este enlace, promoviendo la liberación de la molécula en el interior de la célula. La utilización de grupos amino, como el grupo $\mathrm{N}$-terminal propio del CPP o el grupo épsilon-amino de una lisina para formar un enlace amida con un ácido carboxílico es también una estrategia muy extendida, así como el uso de espaciadores homo o heterobifuncionales como el SMCC (éster 4-(N-maleimidometil) ciclohexano-1-carboxilato de N-hidroxisuccinimida)) para unir ambos componentes. Los espaciadores heterobifuncionales se han utilizado ampliamente para unir los CPPs a diferentes tipos de moléculas, tales como anticuerpos monoclonales, proteínas, tando su potencial terapéutico. Los CPPs desarrollados en los últimos años, podrían solucionar esta limitación, facilitando la entrada al interior de la célula de fármacos/péptidos de acción intracelular, dando lugar a estructuras con un amplio rango de aplicaciones biomédicas. El desarrollo constante en este campo, ha conducido a que siete CPPs (compuesto único o conjugados a otras moléculas terapéuticas) se encuentren en ensayos clínicos y preclínicos para el tratamiento de diversas afecciones (Tabla 3) ${ }^{24}$

A pesar de los esfuerzos realizados por la comunidad científica en las dos últimas décadas, aún no aparecen publicados estudios en humanos en los que se emplee cualquiera de los CPPs, ya sea como agentes terapéuticos o de diagnóstico, lo que denota la presencia de obstáculos que deben superarse, antes de que las

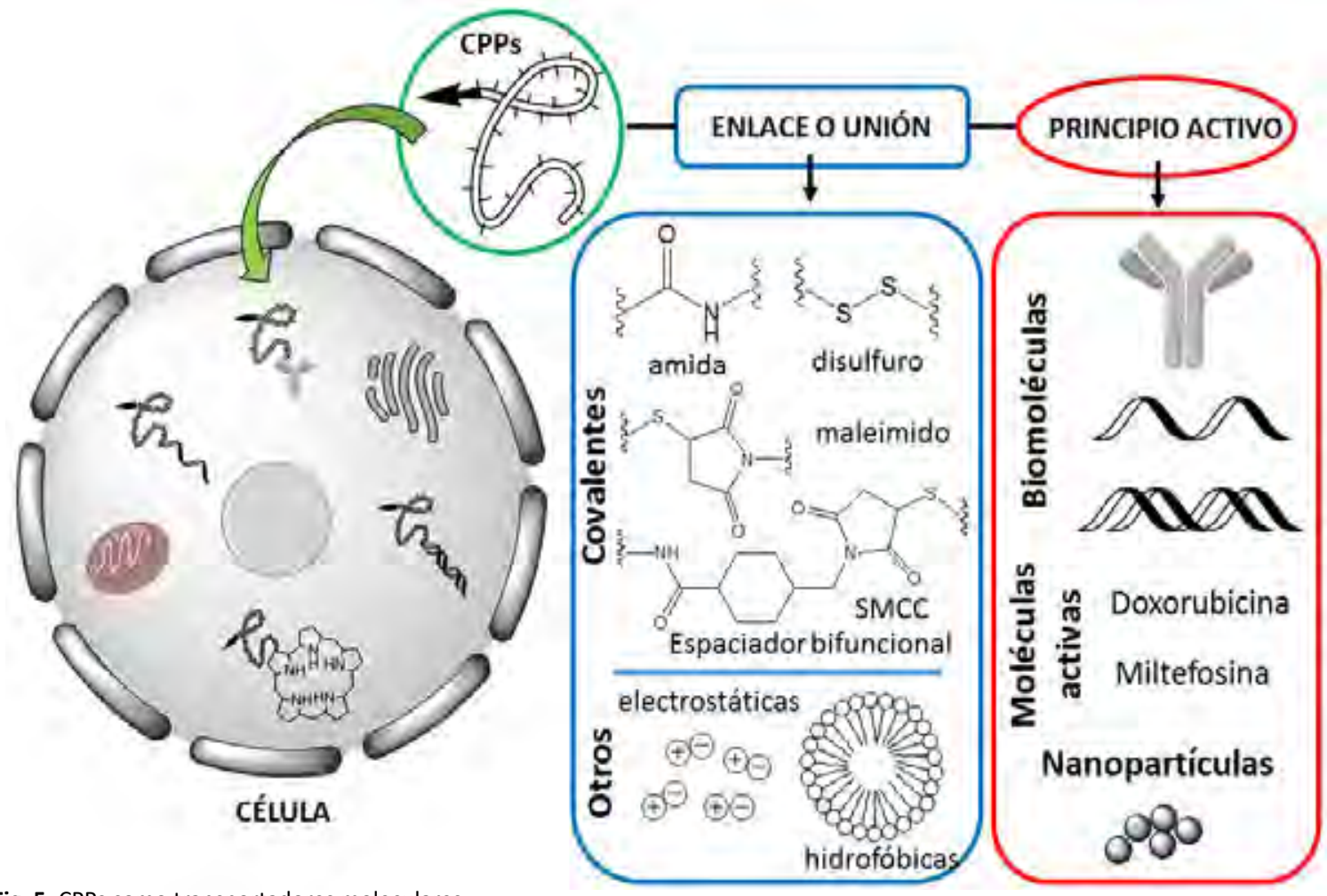

Fig. 5. CPPs como transportadores moleculares.

\section{Polímeros Yón détidos 44 plejos no covalentes entre el CPP y la molécula terapéutica.}

La formación del complejo no covalente entre el CPP y la molécula de interés, involucra interacciones electrostáticas y/o hidrofóbicas (Figura 5). Se conocen varios ejemplos de esta clase de conjugados, como el MPG con la SiRNA, ${ }^{29}$ la interacción de la avidina con el complejo biotina-CPP, ${ }^{45}$ entre otros.

La principal ventaja de este método, es la fácil preparación de estos complejos. Además, los CPPs pueden ser utilizados para conjugar un rango amplio de moléculas sin implicar modificaciones químicas. ${ }^{46}$

Diversos conjugados derivados de fármacos como la doxorubicina y la miltefosina, se han formado a partir de uniones covalentes o no covalentes entre el CPP y el fármaco. Estos fármacos se han conjugado a una gran variedad de CPPs de manera directa o formando parte de nanoencapsulados y se han probado en diferentes modelos para estudiar su capacidad de atravesar membranas citoplasmáticas de distintas líneas celulares, así como la barrera hematoencefálica (BHE) (Tabla 2).

\section{Péptidos con capacidad de atravesar la membrana celular (CPPs) en estudios clínicos.}

Hasta el 2014, más de 60 péptidos terapéuticos se habían introducido en el mercado farmacéutico y cuatro de ellos con elevadas ganancias en el mercado global ( $\mathrm{Ej}$, Copaxone, Lupron, Zoladex y Sandostatin). Sin embargo, ninguno de estos péptidos tienen como diana terapéutica las proteínas intracelulares, limi- aplicaciones potenciales de los CPPs tengan utilidad clínica. El primer factor que obstaculiza el avance en este sentido es el costo sintético, lo cual es una desventaja, especialmente cuando se trata del escalado de la síntesis peptídica con la finalidad de realizar los estudios correspondientes en animales y humanos. Adicionalmente, estos péptidos no son oralmente biodisponibles, lo que trae como consecuencia que en los ensayos clínicos realizados hasta la fecha, se suministren a través de aplicaciones tópicas, o por vía intravenosa. Otra cuestión a tener en cuenta es que los CPPs de tipo catiónico y hidrofóbicos, a pesar de ser transductores potentes y eficientes, presentan una absorción altamente no específica, potenciando los efectos secundarios causados con relación al efecto terapéutico. Por último, como con cualquier medicamento terapéutico nuevo, será imprescindible valorar el efecto de estas nuevas entidades en el riñón, así como la toxicidad hepática que presenten vs el beneficio terapéutico que reporten.

\section{CONCLUSIONES}

Los péptidos que atraviesan la membrana celular (CPPs) pueden definirse como péptidos pequeños de 5-30 aminoácidos de longitud que, gracias a características estructurales y conformacionales definidas, tienen el potencial para transportar numerosos tipos de agentes terapéuticos a través de la membrana celular. Entre las características más comunes para estas entidades resalta la presencia de carga neta positiva, así como el carácter anfipático 


\begin{tabular}{|c|c|c|c|c|}
\hline Firmaco & $\begin{array}{l}\text { Tipo de } \\
\text { unión. }\end{array}$ & GPPs & Madelo & Ref. \\
\hline \multirow[t]{7}{*}{ Doxortibicina } & Covalente & $\begin{array}{l}\text { D-penetratina } \\
\text { SynB1 }\end{array}$ & Ratón y rata (BHE) & 47 \\
\hline & Covalente & Angiopep-2 & Ratón (BHE) & 48 \\
\hline & No covalente & CADY -1 & $\begin{array}{l}\text { Celulas HeLa y } \\
\text { ratones }\end{array}$ & 49 \\
\hline & Covalente & ACPP & $\begin{array}{l}\text { Celulas HT- } 1080 \text { y } \\
\text { MCF-7 }\end{array}$ & 50 \\
\hline & Covalente & oligoarginimas (R8) & Ratón & 31 \\
\hline & Covalente & pVEC-gHo & $\begin{array}{l}\text { Celulas HEK } 293 . \\
\text { U87 y HeLa. ratós }\end{array}$ & 52 \\
\hline & Covalente & $\begin{array}{l}\text { oligoarginuas (R8) y } \\
\text { péptido rico en } \\
\text { prolinas }\end{array}$ & $\begin{array}{l}\text { Células MCF-7. } \\
\text { HT-1080 }\end{array}$ & 2 \\
\hline $\begin{array}{l}\text { Liposomis- } \\
\text { doxonbicina* }\end{array}$ & Covalente & $\begin{array}{l}\text { Tat } \\
\text { (AYGRKKRRQRRR) }\end{array}$ & $\begin{array}{l}\text { Células } \\
\text { endoteliales de los } \\
\text { capilares del } \\
\text { cerebro, C6 y ratón }\end{array}$ & 33 \\
\hline $\begin{array}{l}\text { Doxorubicina- } \\
\text { liposomas" }\end{array}$ & Covalente & PFV & $\begin{array}{l}\text { Células MCF-7, } \\
\text { MCF-7/Adr } 4 \mathrm{~T} 1 . \\
\text { ratón }\end{array}$ & 34 \\
\hline $\begin{array}{l}\text { Micela- } \\
\text { doxorubicinas }\end{array}$ & Covalente & R8-RGD & $\begin{array}{l}\text { Celulas Hela y } \\
293 \mathrm{~T}\end{array}$ & $55^{\circ}$ \\
\hline $\begin{array}{l}\text { Nanoparticulas de } \\
\text { CaCO3- } \\
\text { doxorubicinat }\end{array}$ & $\begin{array}{l}\text { No } \\
\text { covalentes }\end{array}$ & KALA & Células HeLa & 56 \\
\hline $\begin{array}{l}\text { Namotubo: } \\
\text { doxorubicina" }\end{array}$ & Covalente & Angiopep=2 & $\begin{array}{l}\text { Celulas } \\
\text { endoteliales de los } \\
\text { copilares del } \\
\text { serebro. C6 y ratón }\end{array}$ & 57 \\
\hline $\begin{array}{l}\text { Doxorubicina- } \\
\text { liposoma-(Tf*) }\end{array}$ & Covalente & $\begin{array}{l}\text { Tat } \\
\text { Penetratina } \\
\text { Mastoparan }\end{array}$ & $\begin{array}{l}\text { Celulas Daoy, U87 } \\
y \text { bEnd } 3\end{array}$ & 38 \\
\hline $\begin{array}{l}\text { Miltefosina- } \\
\text { BODIPY }\end{array}$ & Covalente & Tat & Leishmania & 39 \\
\hline
\end{tabular}

Table 2. Ejemplos de CPPs transportadores de doxorubicina y miltefosina. HT-1080 (fibrosarcoma humano), MCF-7 (adenocarcinoma de seno humano), HEK 293 (riñon de embrión humano), U87 (similar al epitelio, glioma humano), HeLa (cáncer de cérvico-uterino), HT-29 (carcinoma de colon humano), C6 (células glioma). * El CPP se une de forma covalente al nanocompuesto, mientras que el fármaco está encapsulado en el interior del nanocompuesto.

\begin{tabular}{|c|c|c|c|}
\hline $\begin{array}{l}\text { Conjugado } \\
\text { CPPs-principio } \\
\text { uctivo }\end{array}$ & Aplicación & $\begin{array}{l}\text { Estudios } \\
\text { clinicos }\end{array}$ & Comparia \\
\hline $\mathrm{A} Z \mathrm{X} 100$ & Cicatrices queloides & Fase II & $\begin{array}{l}\text { Capstone } \\
\text { Therapeutics }\end{array}$ \\
\hline RT001 & Arrugas en la piel & Fase II & $\begin{array}{l}\text { Revances } \\
\text { Therapeutics }\end{array}$ \\
\hline KAI- 9803 & Infarto de miocardio & Fase II & $\begin{array}{c}\text { KAI } \\
\text { Pharmaceuticals }\end{array}$ \\
\hline $\mathrm{XG}-102$ & Pérdida de la audición & Fase II & Auris medical \\
\hline $\begin{array}{l}\text { Psorban } \\
\text { (ciclosporina- } \\
\text { poliargmina) }\end{array}$ & Psoriasis & Fase II & CellGate. Ine. \\
\hline$($ RAhx-R) 4 & $\begin{array}{c}\text { Previene el bloqueo } \\
\text { eventual de la vena } \\
\text { transplantada después } \\
\text { de la cingia de baypás } \\
\text { vaseular }\end{array}$ & Fase I & Avio Biophanma \\
\hline p28 & $\begin{array}{l}\text { Tratamiento de tumores } \\
\text { solidos que expresan } \\
\text { p53 y tumores malignos } \\
\text { en el CNS }\end{array}$ & Fase I & clinicaltrials gov \\
\hline ISS P-002 & Vacuna del VIH & Fase I & $\begin{array}{l}\text { Istituto Superiore di } \\
\text { Sanita and Novartis }\end{array}$ \\
\hline DTS-108 & Tratamiento del cancer & Fase 1 & $\begin{array}{c}\text { Drais } \\
\text { Pharmaceuticals y } \\
\text { Diatos } 5 \mathrm{~A}\end{array}$ \\
\hline AV15038 & $\begin{array}{l}\text { Tratamiento de distrofia } \\
\text { muscular de Duchenne }\end{array}$ & $\begin{array}{c}\text { Fase } \\
\text { preclinica }\end{array}$ & AVI BioPharma Ins. \\
\hline
\end{tabular}

Table 3. CPPs que se encuentran en ensayos clínicos. ${ }^{15,24}$ 
de estas estructuras. Otro aspecto importante que augura el éxito de las plataformas terapéuticas que empleen estos compuestos, es sin duda la versatilidad que brindan cuando se trata de formar la unión CPP-principio activo, abarcando una gran variedad de uniones covalentes (enlace amida, enlace tiol, espaciadores homo o heterobifuncionales, etc), así como uniones no covalentes, siendo las interacciones electrostáticas o las interacciones homofóbicas las más reportadas dentro de este contexto.

Aunque los primeros CPPs estudiados fueron de origen natural (Tat, pAntp, MPG, etc), en los últimos años los peptidomiméticos y/o plegómeros peptídicos han ocupado un lugar importante en los estudios realizados, demostrando que su empleo minimiza problemas relacionados con la baja biodisponibilidad, la absorción no específica y la degradación enzimática de las secuencias peptídicas naturales. Como consecuencia, plegómeros peptídicos como los $\gamma$-péptidos sintetizados a partir de la cis- $\gamma$ amino-L-prolina, se encuentran en el punto de mira para su utilización en el desarrollo de plataformas terapeúticas eficientes con un amplio rango de aplicaciones biomédicas.

\section{Referencias bibliográficas}

1. Schneider, M. et al. Crossing biological barriers for advanced drug delivery. Eur. J. Pharm. Biopharm. 84, 239-41 (2013). DOI: 10.1016/j. ejpb.2013.03.009

2. Wang, F. et al. Recent progress of cell-penetrating peptides as new carriers for intracellular cargo delivery. J. Control. Release 174, 12636 (2014). DOI: 10.1016/j.jconrel.2013.11.020

3. Munyendo, W. L., Huixia, L., Benza-Ingoula, H., Baraza, L. D. \& Zhou, J. Cell penetrating peptides in the delivery of biopharmaceuticals. Biomolecules 2, 187-202 (2012). DOI: 10.3390/biom2020187

4. Regberg, J., Srimanee, A. \& Langel, Ü. Applications of Cell-Penetrating Peptides for Tumor Targeting and Future Cancer Therapies. Pharmaceuticals 5, 991-1007 (2012). DOI:10.3390/ph5090991

5. Lee, J. Y., Bae, K. H., Kim, J. S., Nam, Y. S. \& Park, T. G. Intracellular delivery of paclitaxel using oil-free, shell cross-linked HSA--multiarmed PEG nanocapsules. Biomaterials 32, 8635-44 (2011). DOI: 10.1016/j.biomaterials.2011.07.063

6. Nakase, I., Tanaka, G. \& Futaki, S. Cell-penetrating peptides (CPPs) as a vector for the delivery of siRNAs into cells. Mol. Biosyst. 9, 85561 (2013). DOI: 10.1039/C2MB25467K

7. Bai, H. et al. Antisense inhibition of gene expression and growth in gram-negative bacteria by cell-penetrating peptide conjugates of peptide nucleic acids targeted to rpoD gene. Biomaterials 33, 659-67 (2012). DOI: 10.1016/j.biomaterials.2011.09.075

8. Liu, B. R., Liou, J. S., Chen, Y. J., Huang, Y. W. \& Lee, H. J. Delivery of nucleic acids, proteins, and nanoparticles by arginine-rich cell-penetrating peptides in rotifers. Mar. Biotechnol. (NY). 15, 584-95 (2013). DOI: 10.1007/s10126-013-9509-0

9. Galdiero, S. et al. Intracellular delivery: exploiting viral membranotropic peptides. Curr. Drug Metab. 13, 93-104 (2012). DOI: $10.2174 / 138920012798356961$

10. Marín, S., Pujals, S., Giralt, E. \& Merkoçi, A. Electrochemical investigation of cellular uptake of quantum dots decorated with a proline-rich cell penetrating peptide. Bioconjug. Chem. 22, 180-5 (2011). DOI: $10.1021 /$ bc100207w

11. Zappavigna, S., Misso, G., Falanga, A., Perillo, E., Novellino, E., Galdiero, M., Grieco, P., Caraglia, M., Galdiero, S. Nanocarriers Conjugated with Cell Penetrating Peptides: New Trojan Horses by Modern Ulysses. Current Pharmaceutical Biotechnology. 17, 8, 700-722 (2016). DOI: 10.2174/1389201017666160415155145

12. Jiao, C.Y. et al. Translocation and endocytosis for cell-penetrating peptide internalization. J. Biol. Chem. 284, 33957-65 (2009). http:// www.jbc.org/content/284/49/33957.full

13. Guo, Z., Peng, H., Kang, J. \& Sun, D. Cell-penetrating peptides: Possible transduction mechanisms and therapeutic applications (Review). Biomedical reports. 4, 528-534 (2016). DOI: 10.3892/br.2016.639

14. Bechara, C. \& Sagan, S. Cell-penetrating peptides: 20 years later, where do we stand? FEBS Lett. 587, 1693-702 (2013). DOI: 10.1016/j. febslet.2013.04.031

15. Koren, E. \& Torchilin, V. P. Cell-penetrating peptides: breaking through to the other side. Trends Mol. Med. 18, 385-93 (2012). DOI: 10.1016/j.molmed.2012.04.012

16. Derossi, D., Joliot, A. H., Chassaing, G. \& Prochiantz, A. The third helix of the Antennapedia homeodomain translocates through biological membranes. J. Biol. Chem. 269, 10444-50 (1994). http://www. jbc.org/content/269/14/10444.full.pdf

17. Futaki, S. et al. Arginine-rich peptides. An abundant source of membrane-permeable peptides having potential as carriers for intracellular protein delivery. J. Biol. Chem. 276, 5836-40 (2001). DOI 10.1074/jbc.M007540200

18. Wender, P. A., Cooley, C. B. \& Geihe, E. I. Beyond cell penetrating peptides: designed molecular transporters. Drug Discov. Today. Technol. 9, e49-e55 (2012). DOI: 10.1016/j.ddtec.2011.07.004

19. Morris, M. C., Vidal, P., Chaloin, L., Heitz, F. \& Divita, G. A new peptide vector for efficient delivery of oligonucleotides into mammalian cells. Nucleic Acids Res. 25, 2730-6 (1997). http://nar.oxfordjournals.org/content/25/14/2730.full.pdf+html

20. Gros, E. et al. A non-covalent peptide-based strategy for protein and peptide nucleic acid transduction. Biochim. Biophys. Acta 1758, 384-93 (2006). DOI: 10.1016/j.bbamem.2006.02.006

21. Elmquist, A., Lindgren, M., Bartfai, T. \& Langel U. VE-cadherin-derived cell-penetrating peptide, pVEC, with carrier functions. Exp. Cell Res. 269, 237-44 (2001). DOI: 10.1006/excr.2001.5316

22. Krauss, U., Müller, M., Stahl, M. \& Beck-Sickinger, A. G. In vitro gene delivery by a novel human calcitonin (hCT)-derived carrier peptide. Bioorg. Med. Chem. Lett. 14, 51-54 (2004). DOI: 10.1016/j. bmcl.2003.10.014

23. Vlieghe, P. \& Khrestchatisky, M. Peptide-based vectors for bloodbrain barrier targeting and delivery of drugs to the central nervous system. Ther. Deliv. 1, 489-94 (2010). DOI: 10.4155/tde.10.44

24. Milletti, F. Cell-penetrating peptides: classes, origin, and current landscape. Drug Discov. Today 17, 850-60 (2012). DOI: 10.1016/j. drudis.2012.03.002

25. Kaspar, A. \& Reichert, J. M. Future directions for peptide therapeutics development. Drug Discov. Today 18, 807-17 (2013). DOI: 10.1016/j.drudis.2013.05.011

26. Gellman SH. Foldamers: A Manifesto. Acc Chem Res. 1998;31(4):173180. doi:10.1021/ar960298r.

27. Smith, B. J. et al. Structure-guided rational design of $\alpha / \beta$-peptide foldamers with high affinity for BCL-2 family prosurvival proteins. Chembiochem 14, 1564-72 (2013). DOI: 10.1002/cbic.201300351

28. Farrera-Sinfreu, J. et al. A new class of foldamers based on cis-g-amino-L-proline. J. Am. Chem. Soc. 126, 6048-57 (2004). DOI: 10.1021/ ja0398621

29. Morris, M. C., Deshayes, S., Heitz, F. \& Divita, G. Cell-penetrating peptides: from molecular mechanisms to therapeutics. Biol. cell 100, 201-17 (2008). DOI: 10.1042/BC20070116

30. Liu, B. R. et al. Endocytic trafficking of nanoparticles delivered by cell-penetrating peptides comprised of nona-arginine and a penetration accelerating sequence. PLoS One 8, e67100 (2013). DOI:10.1371/ journal.pone.0067100

31. Schafmeister, C. E., Po, J. \& Verdine, G. L. An all-hydrocarbon cross-linking system for enhancing the helicity and metabolic stability of peptides. J. Am. Chem. Soc. 122, 5891-5892 (2000). DOI: $10.1021 / \mathrm{ja} 000563 \mathrm{a}$

32. Ochocki, J. D., Mullen, D. G., Wattenberg, E. V \& Distefano, M. D. Evaluation of a cell penetrating prenylated peptide lacking an intrinsic fluorophore via in situ click reaction. Bioorg. Med. Chem. Lett. 21, 4998-5001 (2011). DOI: 10.1016/j.bmcl.2011.04.138

33. Covic, L., Gresser, A. L., Talavera, J., Swift, S. \& Kuliopulos, A. Activation and inhibition of $\mathrm{G}$ protein-coupled receptors by cell-penetrating membrane-tethered peptides. Proc. Natl. Acad. Sci. U. S. A. 99, 643-8 (2002). DOI: 10.1073/pnas.022460899

34. Watkins, C. L. et al. Cellular uptake, distribution and cytotoxicity of the hydrophobic cell penetrating peptide sequence PFVYLI linked to the proapoptotic domain peptide PAD. J. Control. Release 140, 237-44 (2009). DOI: 10.1016/j.jconrel.2009.04.028

35. Oehlke, J. et al. Cellular uptake of an a-helical amphipathic model peptide with the potential to deliver polar compounds into the cell interior non-endocytically. Biochim. Biophys. Acta 1414, 127-39 (1998). doi:10.1016/S0005-2736(98)00161-8

36. Deshayes, S., Decaffmeyer, M., Brasseur, R. \& Thomas, A. Structural polymorphism of two CPP: an important parameter of activity. Biochim. Biophys. Acta 1778, 1197-205 (2008). DOI:10.1016/j.bbamem.2008.01.027

37. Pujals, S. \& Giralt, E. Proline-rich, amphipathic cell-penetrating peptides. Adv. Drug Deliv. Rev. 60, 473-84 (2008). DOI:10.1016/j. addr.2007.09.012

38. Li, L., Geisler, I., Chmielewski, J. \& Cheng, J.-X. Cationic amphiphilic polyproline helix P11LRR targets intracellular mitochondria. J. Con- 
trol. Release 142, 259-66 (2010). DOI:10.1016/j.jconrel.2009.10.012

39. Fernández-Carneado, J., Kogan, M. J., Castel, S., \& Giralt, E. (2004). Potential peptide carriers: amphipathic proline-rich peptides derived from the N-terminal domain of gamma-zein. Angewandte Chemie (International Ed. in English), 43(14), 1811-4. http://doi. org/10.1002/anie.200352540

40. Sadler, K., Eom, K. D., Yang, J.-L., Dimitrova, Y. \& Tam, J. P. Translocating proline-rich peptides from the antimicrobial peptide Bactenecin 7. Biochemistry 41, 14150-157 (2002). DOI: 10.1021/bi026661l

41. Farrera-Sinfreu, J., Giralt, E., Castel, S., Albericio, F. \& Royo, M Cell-penetrating cis $-\gamma$-amino-L-proline-derived peptides. J. Am. Chem. Soc. 127, 9459-68 (2005). DOI: 10.1021/ja051648k

42. Gorrea, E., Carbajo, D., Gutiérrez-Abad, R., Illa, O., Branchadell, V., Royo, M., Ortuño, R.M. Searching for new cell-penetrating agents: hybrid cyclobutane-proline $\gamma, \gamma$-peptides. Org Biomol Chem. 10, 20, 4050-4057(2012). DOI: 10.1039/c2ob25220a.

43. Cavalli, S., Carbajo, D., Acosta, M., Lope-Piedrafita, S., Candiota, A. P., Arús, C., Royo, M., \& Albericio, F. Efficient g-amino-proline-derived cell penetrating peptide-superparamagnetic iron oxide nanoparticle conjugates via aniline-catalyzed oxime chemistry as bimodal imaging nanoagents. Chem. Commun., 48, 5322-5324 (2012). DOI: $10.1039 / \mathrm{c} 2 \mathrm{cc} 17937 \mathrm{~g}$

44. Lelle, M., Frick, S. U., Steinbrink, K. \& Peneva, K. Novel cleavable cell-penetrating peptide-drug conjugates: synthesis and characterization. J. Pept. Sci. 20, 323-33 (2014). DOI: 10.1002/psc.2617

45. Pooga, M. \& Langel, Ü. Synthesis of cell-penetrating peptides for cargo delivery. Methods Mol. Biol. 298, 77-89 (2005). DOI: 10.1385/159259-877-3:077

46. Sarko, D. et al. The Pharmacokinetics of cell-penetrating peptides. Mol. Pharm. 7, 2224-31 (2010). DOI: 10.1021/mp100223d

47. Rousselle, C. et al. New advances in the transport of doxorubicin through the blood-brain barrier by a peptide vector-mediated strategy. Mol. Pharmacol. 57, 679-86 (2000). DOI: 10.1124/mol.57.4.679

48. Ché, C. et al. New Angiopep-modified doxorubicin (ANG1007) and etoposide (ANG1009) chemotherapeutics with increased brain penetration. J. Med. Chem. 53, 2814-24 (2010). DOI:10.1021/jm9016637

49. Li, Y. et al. Self-assembled peptide (CADY-1) improved the clinical application of doxorubicin. Int. J. Pharm. 434, 209-14 (2012). DOI: 10.1016/j.ijpharm.2012.06.003

50. Shi, N.-Q., Gao, W., Xiang, B. \& Qi, X. R. Enhancing cellular uptake of activable cell-penetrating peptide-doxorubicin conjugate by enzymatic cleavage. Int. J. Nanomedicine 7, 1613-21 (2012). DOI: 10.2147/IJN.S30104
51. Nakase, I., Konishi, Y., Ueda, M., Saji, H. \& Futaki, S. Accumulation of arginine-rich cell-penetrating peptides in tumors and the potential for anticancer drug delivery in vivo. J. Control. Release 159, 181-8 (2012). DOI:10.1016/j.jconrel.2012.01.016

52. Eriste, E. et al. Peptide-based glioma-targeted drug delivery vector gHoPe2. Bioconjug. Chem. 24, 305-13 (2013). DOI: 10.1021/ bc300370w

53. Qin, Y. et al. Liposome formulated with TAT-modified cholesterol for improving brain delivery and therapeutic efficacy on brain glioma in animals. Int. J. Pharm. 420, 304-12 (2011). DOI: 10.1016/j. ijpharm.2011.09.008

54. Cai, D. et al. Hydrophobic penetrating peptide PFVYLI-modified stealth liposomes for doxorubicin delivery in breast cancer therapy. Biomaterials 35, 2283-94 (2014). DOI:10.1016/j.biomaterials.2013.11.088

55. Chen, J.-X. et al. Construction of surfactant-like tetra-tail amphiphilic peptide with RGD ligand for encapsulation of porphyrin for photodynamic therapy. Biomaterials 32, 1678-84 (2011). DOI: 10.1016/j. biomaterials.2010.10.047

56. Zhao, D., Zhuo, R.-X. \& Cheng, S.-X. Modification of calcium carbonate based gene and drug delivery systems by a cell-penetrating peptide. Mol. Biosyst. 8, 3288-94 (2012). DOI: 10.1039/C2MB25233C

57. Ren, J. et al. The targeted delivery of anticancer drugs to brain glioma by PEGylated oxidized multi-walled carbon nanotubes modified with angiopep-2. Biomaterials 33, 3324-33 (2012). DOI: 10.1016/j. biomaterials.2012.01.025

58. Sharma G, Modgil A, Zhong T, Sun C, Singh J. Influence of shortchain cell-penetrating peptides on transport of doxorubicin encapsulating receptor-targeted liposomes across brain endothelial barrier. Pharm Res. 2014;31(5):1194-1209. doi:10.1007/s11095-013-1242-x.

59. De la Torre, B. G. et al. A BODIPY-embedding miltefosine analog linked to cell-penetrating Tat(48-60) peptide favors intracellular delivery and visualization of the antiparasitic drug. Amino Acids 46, 1047-58 (2014). DOI: 10.1007/s00726-013-1661-3

Recibido: 17 de septiembre de 2016.

Aprobado: 12 de noviembre de 2016. 